\title{
Los Modelos de Orientación Estratégica (MOEs): una adaptación del enfoque estratégico para el rediseño organizativo en las Administraciones públicas *
}

\section{Carles Ramió y Miquel Salvador **}

\section{Introducción}

A partir de la segunda mitad de los años noventa, y mientras se desarrollaba la discusión sobre qué actividades deben ser realizadas desde el sector público, muchas Administraciones se movían en un contexto de programas de modernización en constante revisión y de planes estratégicos que se mantenían como referencias lejanas o meramente enunciativas. Paralelamente, y para dar respuesta a los retos que plantea un entorno cada vez más complejo y cambiante, muchas Administraciones optaban por la introducción de técnicas de gestión privadas, de carácter básicamente operativo, sin sopesar suficientemente su adecuación a su realidad organizativa ni considerar su validez en un entorno de sector público. Esta traslación casi mimética Llevó a fracasos y fue fuente de frustración en diversas áreas -recúerdense, por ejemplo, los intentos de introducir la dirección por objetivos, las modificaciones en los mecanismos de presupuestación o la propia planificación estratégica-.

De esta situación se desprendía una falta de orientaciones claras que marcasen una dirección hacia donde plantear el desarrollo organizativo de las Administraciones públicas para dar respuesta a los cambios que se producían tanto en su misión genérica como en buena parte de los objetivos en que ésta se concretaba.
La ausencia de criterios orientadores no era obstáculo, sin embargo, para iniciar modificaciones puntuales en diversos ámbitos de la organización —aparte de la introducción de técnicas de gestión privada que ya se ha comentado-. Estas transformaciones pretendían dar respuestas a problemas concretos que, diagnosticados tardíamente, requerían de una actuación acelerada. Planteadas sin una visión integral de la organización, no era extraño que las modificaciones diseñadas chocasen con la cultura o las dinámicas de funcionamiento de las organizaciones públicas y, en muchas ocasiones, no llegasen a implementarse efectivamente.

De este diagnóstico de situación se deriva que, más allá de cambios incrementales, el desarrollo de una verdadera capacidad de respuesta en el ámbito de las organizaciones públicas requiere de una reflexión estratégica que conecte el ámbito organizativo y las técnicas que éste utiliza, con la misión y los objetivos de la Administración. Aunque esta reflexión ya aparece en la teoría de la planificación estratégica, en pocas ocasiones se ha convertido en una realidad efectiva, siendo una de sus causas la ausencia de un marco específico de reflexión que apoye este ámbito de la dirección estratégica. A partir de la constatación de ambos procesos, y a través de la consideración de diversos casos aplicados —desarrollados por los propios autores del artículo- se definen los Modelos de Orientación Estratégica (MOEs). 


\section{El marco teórico de los MOEs: la dirección estratégica y la planificación en las Administraciones públicas}

La Dirección Estratégica es un término de gestión empresarial acuñado en la década de los ochenta para denominar la disciplina tradicionalmente conocida en las escuelas de negocios como «política de empresa» (GarCía FalCón, 1995). No hay consenso en las Ciencias Empresariales en la definición de Dirección Estratégica, ya que depende de lo que cada autor entiende por «estrategia». Es curioso que un concepto y una disciplina de tan difícil definición haya generado una abundante literatura y práctica de empresa durante los últimos quince años. La Dirección Estratégica se ha convertido en una herramienta básica en la "gestión del futuro» de las empresas privadas que sustituye a la anticuada herramienta de la planificación estratégica, tótem durante los años setenta y parte de los ochenta y en desuso en la actualidad. De todos modos, aunque en la gestión pública la planificación estratégica todavía sobrevive, la Dirección Estratégica, en cambio, ha tenido hasta el momento poca repercusión.

¿Cuál es la diferencia entre planificación estratégica y dirección estratégica? La planificación estratégica consiste en un sis. tema de dirección de anticipación al cambio como una reacción a un entorno cambiante, donde las técnicas clásicas de carácter cuantitativo y de extrapolación resultaban ineficaces (nos referimos a las técnicas de «planificación a largo plazo» que predominaron en la gestión empresarial de los años sesenta). La planificación estratégica fundamenta sus esfuerzos en unos análisis de tipo cualitativo que intentan explicar la naturaleza de los cambios del entorno. Es decir, la planificación estratégica tiene una amplia base analítica y conceptual que deja de lado un instrumental económico cuantificable y pseudocientífico que dominaba en la denominada «planificación a largo plazo». Pero la Planificación Estratégica ha dado lugar a muchos fracasos debido a sus déficit para detectar problemas emergentes y para percibir las «señales débiles» de entorno, debido a su falta de integración con los mecanismos de implementación y de control y, finalmente, debido a su cuestionable ratio coste/beneficio. Es evidente que el principal problema de la Planificación Estratégica en su aplicación en la Administración pública es su consideración, formal o real, como un proceso diferente al de la gestión (un problema similar al que ha experimentado en el sector privado). La Dirección Estratégica, al igual que la planificación, tiene como objetivo prever y entender la lógica y la naturaleza de los cambios del entorno. Pero su principal ventaja reside en vincular la planificación estratégica con el resto de los elementos de la organización (las estructuras, los procesos, los recursos humanos y tecnológicos, etc.). No se planifica por un lado y se gestiona por otro, sino que se planifica para gestionar mejor y se hace un gran esfuerzo en la gestión del cambio. Esto significa que el diseño de las estrategias no es una competencia que está ubicada en una unidad especializada, con escasas conexiones con el resto de la organización, como ocurría con la planificación estratégica. La Dirección Estratégica se fundamenta en una descentralización participativa de la planificación y del diseño de estrategias donde participan todos los ámbitos de gestión de una organización.

\begin{tabular}{|c|c|c|}
\hline $\begin{array}{r}\text { Diferencias } \\
\text { estra }\end{array}$ & $\begin{array}{l}\text { Tabla } 1 \\
\text { re los sistemas } \\
\text { ca y dirección }\end{array}$ & $\begin{array}{l}\text { anificación } \\
\text { égica }\end{array}$ \\
\hline Factores & Planificación estratégica & Dirección estratégica \\
\hline $\begin{array}{l}\text { Naturaleza entomo } \\
\text { Epoca de desamollo } \\
\text { Tipo de proceso directivo } \\
\text { Honizonte } \\
\text { Formulución estrategias } \\
\text { Estilo de direción } \\
\text { Enfoqine de las cambios del } \\
\text { entiono }\end{array}$ & $\begin{array}{l}\text { Adaptativo } \\
\text { Años sesenta y setenta } \\
\text { Estructurado y previsional } \\
\text { A largo plazo } \\
\text { Centralizado } \\
\text { Tecnocrático } \\
\text { Estático }\end{array}$ & $\begin{array}{l}\text { Inestable } \\
\text { Años ochenta y noventa } \\
\text { No estructurado, flexible, } \\
\text { oportunista. } \\
\text { A corto, medio y largo } \\
\text { plazo } \\
\text { Descentralizado } \\
\text { Creativo } \\
\text { Dinámico }\end{array}$ \\
\hline
\end{tabular}

Fuente: BuENo, E. (1987), Dirección Estratégica de la Empresa, Madrid: Ediciones Pirámide.

Desde nuestro punto de vista, la principal virtud de la Dirección Estratégica es su conexión directa con la organización, con los distintos elementos organizativos: la Dirección Estratégica no es algo ajeno a la organización, sino que emana de la misma. MiNTZBERG y QuinN en un reading sobre el proceso estratégico (1993) otorgan mucha importancia a la vinculación entre la estrategia y los elementos organizativos. En esta obra incluye un artículo de los gurus Waterman, Peters y Philips denominado «el esquema de los siete círculos» (1993). en el que definen la actividad estratégica de la organización como la vinculación entre los objetivos y la estrategia con la estructura, los sistemas, el estilo, las habilidades y el staff o personal de apoyo. Estos elementos se configuran en «las siete brújulas de una organización: cuando las siete agujas apuntan en la misma dirección tenemos una organización organizada». GalBRATTH (1993), por su parte, plantea algo parecido al vincular la estrategia con los objetivos, el personal, la estructura, los procesos y los sistemas de retribución. 
En las Administraciones públicas existe todavía la tendencia, propia de la planificación estratégica, a planificar, por un lado, y a organizar, implementar y controlar, por otro. Planificar se ha convertido, en un nivel simbólico, en sinónimo de modernización y de innovación. La mayoría de las entidades locales, por ejemplo, tienen sus propios planes estratégicos, las universidades también, etc. Una metodología de planificación bastante simple basada en un diagnóstico estructurado en puntos fuertes, puntos débiles, oportunidades, amenazas... tiene como resultado la definición de una misión, una visión, unas líneas estratégicas, unos objetivos estratégicos, etc. Resultado: un plan estratégico o un plan director elaborado por una consultora ajena a la organización o por una unidad staff de la propia organización que recibe el apoyo formal de la dirección y, en las ocasiones que se ha utilizado una metodología participativa, recibe el apoyo de la mayor parte de los ámbitos de gestión de la organización pública. ¿Qué sucede después? Si hay fortuna, el plan estratégico o plan director se convierte en una referencia real (no sólo formal) de la organización, pero sin que los elementos organizativos tengan la capacidad de adaptarse a estas nuevas necesidades. Hay una desconexión muy clara entre la planificación y la organización que hace poco viable alcanzar la mayoría de los objetivos estratégicos.

A nivel de análisis organizativo también se puede detectar un déficit en vincular el análisis y mejora de los distintos elementos que configuran una organización pública con sus objetivos y con su orientación estratégica. Un estudio organizativo analiza los elementos organizativos elaborando un diagnóstico donde se hace mención a aquellos elementos que resultan disfuncionales y a aquellos elementos que se ajustan a las necesidades de la organización. Al diagnóstico le sucede una propuesta organizativa donde se plantean un conjunto de cambios, de mayor o menor alcance, que tienen como objetivo superar las disfunciones previamente detectadas y potenciar los elementos funcionales. Los estudios organizativos en la Administración pública presentan muchos problemas que los hacen poco fiables y poco útiles para conseguir una transformación positiva de las organizaciones auditadas. Los problemas son muy extensos: la autoría de la mayoría de los estudios organizativos corre a cargo de consultoras que no acaban de comprender los problemas específicos de las organizaciones públicas (los conceptos e instrumentos de auditoría están diseñados para organizaciones privadas y no sirven para organizaciones públicas), los miembros de la organización auditada desconfían del proceso de cambio y bloquean el mismo, etc. La literatura ha buscado soluciones a todos estos problemas (Mas y Ramió, 1997). En efecto, todos estos déficit y problemas pueden solucionarse y conseguir transformar las organizaciones públicas alcanzando diseños mucho más racionales. Pero, cel cambio organizativo hacia dónde se dirige?, ¿el cambio organizativo que se propone está en consonancia con los objetivos estratégicos de la organización?
En este sentido, los estudios organizativos están obsesionados en responder a la pregunta ¿cómo?: ¿cómo funciona la organización?; ¿cómo funcionan sus recursos humanos?; ¿cómo podemos mejorar la organización?; ¿cómo podemos mejorar la estructura administrativa?, etc. La obsesión por el icómo?, que tiene una orientación muy instrumental, no sirve de nada si antes no nos cuestionamos el iqué? (objetivos): ¿qué hace la organización?; ¿qué debería hacer la organización?; ¿qué va a hacer la organización en el futuro?. No vincular el qué con el cómo implica ubicar en departamentos estancos, por una parte, a los objetivos y las estrategias y, por otra, al resto de los elementos organizativos.

Una forma de vincular el qué con el cómo de las organizaciones lo proporciona la Dirección Estratégica. De todos modos, en este artículo no se plantea desarrollar la Dirección Estratégica en la Administración pública, sino utilizar la misma para plantear y proponer opciones organizativas acordes con los objetivos estratégicos de la organización objeto de estudio. Se trata, en definitiva, de enriquecer conceptualmente los clásicos estudios organizativos que se fundamentan en la dicotomía diagnóstico-propuesta y elaborar con carácter previo un esquema conceptual que presente hacia dónde puede moverse la organización (objetivos y estrategias) en el futuro y, en función de las diferentes posibilidades, diseñar modelos organizativos en consonancia. Cuando se plantea el diagnóstico y las propuestas, la orientación es muy instrumental, mientras que, cuando se plantean las diferentes opciones estratégicas de actuación de la organización pública objeto de análisis y los modelos organizativos alternativos, la orientación es básicamente teórica.

Como se podrá percibir más adelante, lo que se pretende es presentar un conjunto de modelos extremos, totalmente coherentes en todas sus dimensiones, que tienen un carácter ideal, que difícilmente coinciden o coincidirán con una realidad siempre híbrida y ecléctica. Pero la elección, más o menos aproximada, de uno de estos modelos permite la elaboración de un diagnóstico y, especialmente, la presentación de unas propuestas organizativas que se ajusten a las necesidades derivadas de los objetivos y estrategias de la organización en el futuro. De este modo, el cambio organizativo plantea mejoras no justificables en sí mismas, sino que están en función de los objetivos y de las estrategias de la organización. La contribución de estos modelos no reside en definir los objetivos y las estrategias de una organización pública, que es una actividad política que corresponde al nivel directivo de la propia organización, sino que reside en plantear un modelo organizativo coherente con las necesidades del entorno y del intorno de la organización. De todos modos, no puede obviarse que el proceso de definición de los distintos modelos organizativos alternativos, en función de las distintas estrategias orientadas a alcanzar los objetivos organizativos, favorece un proceso de reflexión y de redefinición de los propios objetivos y estrategias. 


\section{El marco conceptual: los Modelos de Orientación Estratégica (MOEs) y los Configuradores Estratégicos de la Organización (CEOs)}

A partir de un diagnóstico de situación del contexto y de la situación interna de una organización, el desarrollo conceptual de los MOEs como instrumento de apoyo al rediseño organizativo tiene su origen en la reflexión sobre la necesidad de un marco orientador de la transformación de las Administraciones públicas (centralización o descentralización, gestión directa o gestión externalizada, etc. En todo caso, la definición conceptual de los MOEs se relaciona directamente, en general, con la realidad organizativa de las Administraciones públicas $y$, en particular, con las especificidades a nivel de contexto y de gestión de la organización pública objeto de análisis.

\subsection{Los Modelos de Orientación Estratégica (MOEs)}

Considerando ambas premisas, los MOEs se definen como modelos ideales, es decir, no reales, de desarrollo organizativo, definidos a partir de la consideración de las variables clave que ofrecen un criterio orientador tanto para la estructura como para las dinámicas de funcionamiento que puede tomar la organización para realizar con éxito la misión y los objetivos que tiene predefinidos. Las variables clave, definidas en forma de dilemas o dicotomias, sirven de base para el diseño de escenarios de desarrollo organizativo a partir de los cuales ubicar los MOEs.

Una vez definidos los MOEs en base a los escenarios definidos por las variables clave, el siguiente paso es la selección de aquel que se considere más adecuado para alcanzar los objetivos que tiene planteados la organización. A partir de la opción seleccionada se dispone de un referente para valorar la coberencia de las modificaciones que se proponen introducir, tanto las de carácter puntual como las que supongan un cambio más importante en la organización, así como las que se refieren a la estructura orgánica como a las referidas a las dinámicas de funcionamiento.
Tal como se han definido, los MOEs no incluyen el debate o la discusión sobre la razón de ser o la misión de la organización. Ello supone ubicar a esta técnica en el campo de la dirección estratégica, dando por sentado que el ámbito temático de actuación de buena parte de las Administraciones suele venir dictado externamente y no cabe plantear su redefinición, como mínimo en los términos en que se daría en una empresa privada. Ésta es una tarea política, aunque no se puede ocultar que la definición de las variables clave que vertebran los MOEs puedan generar un cierto debate político y, con ello, llegar a reconsiderar la coherencia de los objetivos y de las estrategias de la organización pública objeto de estudio.

Para entendernos, aunque difícilmente una Administración puede cambiar su objeto de actuación, sí puede transformar su organización, sus mecanismos de gestión y sus dinámicas de trabajo para realizar su misión de otra manera que considere más oportuna. Algunas opiniones consideran que cambiar la manera de prestar un servicio, ya sea por un proceso de externalización o por un cambio en las dinámicas de actuación a través de las cuales se presta, supone, en realidad, cambiar el servicio. Aun reconociendo dichas implicaciones, la definición de los MOEs considera la misión de la organización como una variable independiente.

Así entendida, la elaboración de los MOEs supone adoptar un enfoque de reingeniería en la medida que en su configuración mantiene estable la misión para centrarse en los elementos organizativos. La siguiente tabla permite contrastar la técnica en relación a otros enfoques de análisis, a partir de su incidencia sobre la misión y la estructura organizativa.

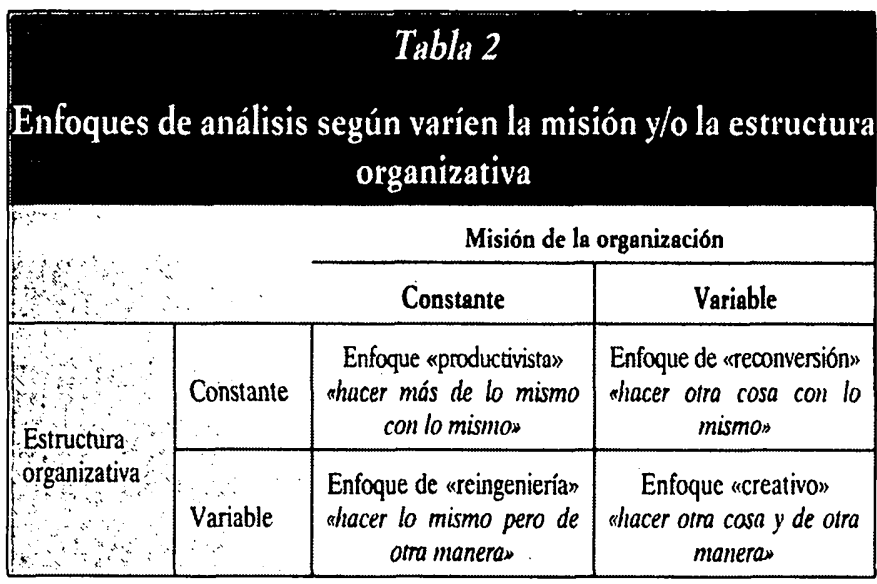

Partiendo del enfoque de reingeniería, el tipo de preguntas que guian la selección de las variables clave a partir de las cuales definir los escenarios de desarrollo organizativo, como base a partir de la cual definir los MOEs, se refieren a cómo la organización está desarrollando sus funciones, a través de qué estructuras, con qué dinámicas de trabajo, con qué tipo de recursos huma- 


\section{Grafico 1}

\section{Ejemplo de presentación gráfica de las variedades clave de la organización para la definición de escenarios}

\section{de desarrollo organizativo y configuración de los MOEs}

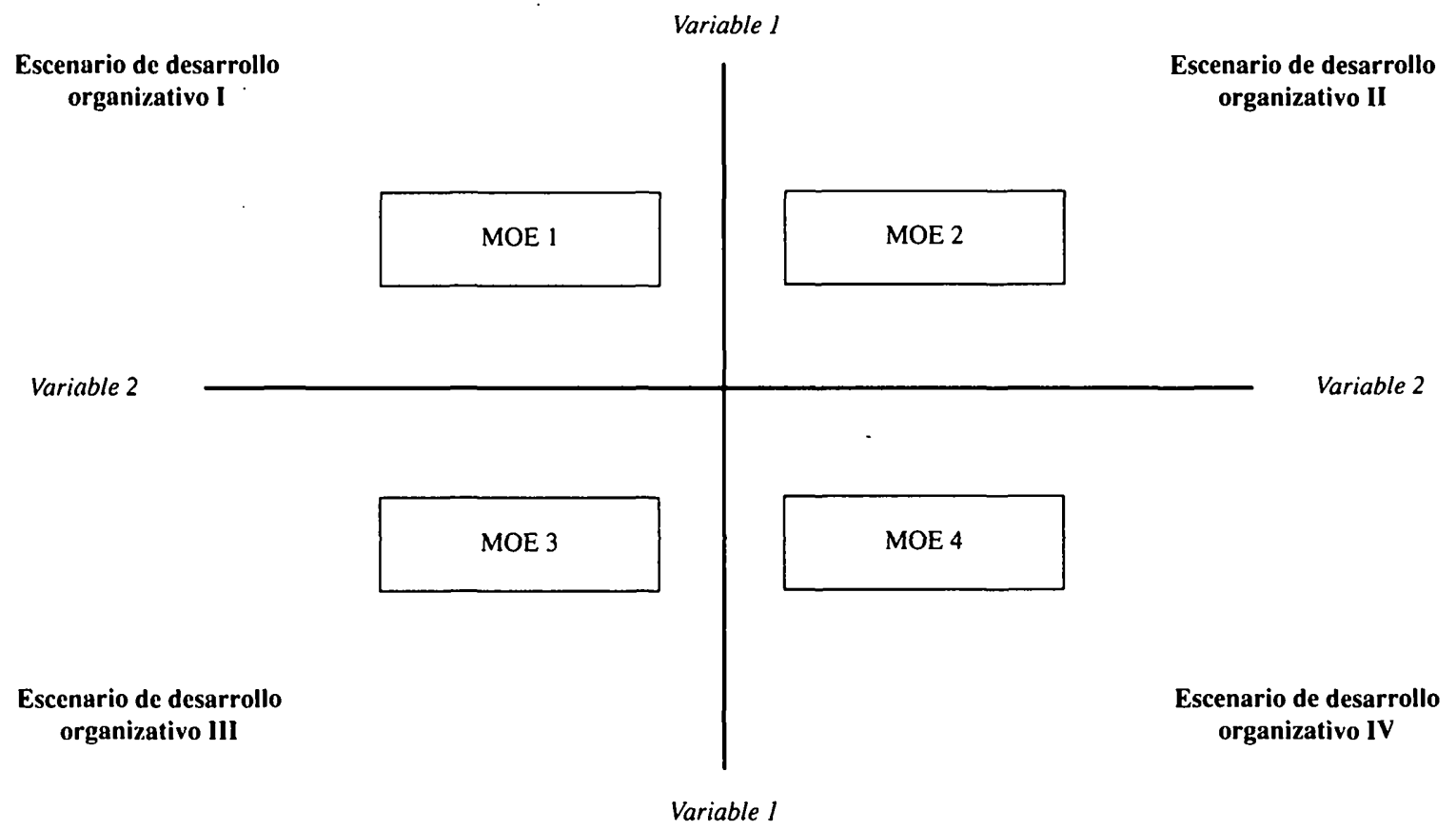

Fucntc: Elabomación propia.

nos y con qué estrategia de actuación. Más concretamente, y tomando la pregunta sobre «qué» hace la organización como un dato externo, se trataría de profundizar en:

a) "cómo» lo hace: las dinámicas de trabajo, el grado de estandarización y normalización de procedimientos, etc.;

b) «con qué» medios cuenta para hacerlo: recursos materiales y tecnológicos para desarrollar su actividad y, sobre todo, los recursos humanos —capacidades, habilidades, actitudes, clima laboral-;

c) «quién» actúa en la organización: desde los perfiles directivos hasta los líderes informales de la organización;

d) «cuándo» actúa: los «ritmos» de la organización en referencia a sus períodos de actuación, a su capacidad de actuación a medio y largo plazo.

Una vez realizada la primera aproximación a la realidad organizativa que se desprende de las anteriores preguntas, conviene introducir la dimensión explicativa e intentar entender el «por qué» la organización funciona de esta manera y «bacia dónde» se dirige desde su posición actual - hacia dónde conducen las dinámicas actuales de trabajo de la organización-.

El diagnóstico que se deriva de la consideración conjunta de los elementos comentados sirve como base a partir de la cual se seleccionan las variables relevantes que contribuyen a definir los escenarios de desarrollo organizativo del caso analizado. Estimando la multiplicidad de opciones que aparecen, una correcta elaboración de los MOEs exige tomar opción por aquellas variables que contienen una mayor capacidad explicativa tanto de la realidad organizativa como de su posible desarrollo. El grado de descentralización o el nivel de externalización con que desarrolle sus funciones la organización son ejemplos del tipo de variables a las que se hace referencia. A partir de su expresión en forma de dicotomías o ejes con valores extremos, se sigue la ubicación de los modelos organizativos ideales hacia los que, potencialmente, puede tender la organización actual (Gráfico 1).

\subsection{Los Configuradores Estratégicos de la Organización (CEOs)}

La ubicación de los MOEs permite una primera caracterización de sus rasgos básicos a partir de las variables que se han utilizado para diseñar los escenarios de desarrollo estratégico. Sin embargo, y siguiendo la orientación hacía la reflexión que se les supone, su definición debe ampliarse considerando 
su impacto sobre los ámbitos clave de la organización. Se busca con ello sentar las bases de una visión integral de la organización que se desprende de cada una de las opciones representadas por los MOEs. Para realizar dicha concreción se definen los denominados Configuradores Estratégicos de la Organización o CEOs.

Los CEOs son los ámbitos clave que permiten definir o tipificar los rasgos sustantivos de la organización atendiendo, en cada caso, a la orientación estratégica que se desprende del MOE que representan. La definición de los CEOs parte de un conocido artículo de Waterman, Peters y PhILIPS denominado «el esquema de los siete círculos» (1993) publicado originalmente en 1980 que ha tenido un gran impacto en las Ciencias Empresariales y, también, en la gestión pública y en la Ciencia Politica. Sue RICHARDS (1996), por ejemplo, planteaba los ejes de definición del nuevo partido laborista británico a partir de la victoria en las elecciones de Tony Blair. Los siete círculos también son reconocidos en la literatura organizativa como las «siete eses», siguiendo las iniciales -en inglés- de cada uno de los ámbitos clave de la organización: superordinate goals (en referencia a la misión y que, en el caso de los MOEs, se considera como un dato exógeno), style, system, strategy, staffing, skills y structure. Sin embargo, en su adaptación a cada realidad organizativa concreta, conviene apuntar la necesidad de realizar una interpretación adecuada de cuáles de los citados elementos revisten una mayor importancia y en cuáles el margen o la necesidad de modificación es menor.

Así, partiendo de esta lista inicial, los CEOs que, dada su relevancia, conviene definir con mayor frecuencia para caracterizar un MOE, son:

1. Estrategia (strategy): hace referencia a la orientación del cambio que supone el MOE y a cómo este cambio pretende llevarse a cabo a partir de la situación actual (cambio radical o incremental, paulatino o drástico, y todas aquellas características relevantes para la organización sobre la que se plantea la reflexión).

2. Estilo (style): las características concretas de la estrategia de desarrollo del MOE a partir de dos dimensiones: su carácter anticipativo o reactivo y su carácter participativo o no participativo. Su caracterización permite tipificar el MOE en cuanto a la manera con la que afronta el proceso de cambio.

3. Sistema (system): que trata las relaciones que se establecen en el MOE tanto con el entorno externo a la organización (que va desde los agentes propiamente externos a los demás departamentos de la misma administración y los organismos transversales de la misma), como con su intorno organizativo (que incluye el conjunto de unidades que conforman la organización y sobre las que existe una mayor capacidad de actuación).

4. Estructura (structure): hace referencia a la estructura de divisionalización, de jerarquía y al diseño de los mecanismos de coordinación que adoptará el MOE para organizar las unidades que tiene adscritas, así como los cambios mas importantes que comporta su adopción. Se incluye también en este apartado la referencia al grado de descentralización y de autonomía que se asocian al modelo.

5. Personal (staffing y skills): en este apartado se recogen las implicaciones que supone el desarrollo del MOE sobre los recursos humanos de la organización, tanto en lo que se refiere a las capacidades y a las habilidades profesionales, como a las actitudes, la motivación y la integración en el proyecto de cambio. También resulta indicado, en buena parte de los casos, recuperar en este punto las implicaciones y/o necesidades que plantea la consecución del MOE sobre el sistema de gestión de los recursos humanos.

6. Procedimiento: este apartado se considera oportuno en ciertos casos cuando el desarrollo de un modelo estratégico va asociado a la introducción de cambios importantes en las dinámicas de trabajo de la organización, más allá de lo que se apunta en el apartado referido a la estructura.

A partir de la consideración de los diferentes CEOs se dispone de una descripción más concreta de los distintos modelos alternativos formulados, con especial atención a sus implicaciones en los diferentes ámbitos organizativos, aproximando el carácter «ideal» del modelo a los rasgos característicos de la organización que se toma como punto de partida. La presentación de los MOEs apoyada con la descripción de sus configuradores estratégicos representa el primer paso hacia la introducción de una visión integral y estratégica de la organización y sienta las bases sobre las que desarrollar la discusión con los diferentes agentes del organismo analizado.

\subsection{Negociación y comunicación alrededor de los MOEs: la importancia del proceso}

La discusión sobre los escenarios de desarrollo organizativo y sobre los MOEs que se definen a partir de su consideración enlaza con la dinámica participativa que rodea todo el proceso de definición, diseño y desarrollo de estos modelos estratégicos. De hecho, la interlocución con los distintos agentes de la organización y con aquellos más relevantes de su entorno de referencia se inicia en la fase de diagnóstico, etapa previa a la selección de las variables clave que dan pie a la definición de los escenarios de desarrollo organizativo. Conviene insistir en este aspecto en la medida que, tanto en lo que se refiere al contenido como al proceso de diseño e implementación de los MOEs, la implicación de los diferentes agentes organizativos reviste un papel fundamental que no se debe descuidar, pues representa una parte muy importante del valor añadido que aporta el desarrollo de esta técnica.

En la medida que la discusión sobre los MOEs se refiere a modelos ideales, es decir, no reales, resulta más fácil generar 
un proceso creativo entre los diferentes agentes de la organización en el que aparecen también los elementos más críticos que en una propuesta de carácter cerrado y de aplicación inmediata quedarían excluidos. Considerando que se discute sobre modelos y no sobre realidades específicas que pueden afectar a la situación actual de forma directa - como mínimo a corto plazo-, resulta más fácil que salgan a la luz aquellas posiciones opuestas a la configuración actual de las que se pueden obtener conclusiones interesantes para el diseño de un escenario estratégico.

Posteriormente, y a partir de la definición de los configuradores estratégicos o CEOs, la discusión puede enriquecerse a través de la consideración puntual de las diferentes implicaciones de los modelos definidos sobre cada uno de los ámbitos relevantes de la organización. Esta línea de reflexión conecta directamente con la revisión de la viabilidad de los diferentes cambios que se proponen introducir en la organización, atendiendo tanto a su realidad actual como a la orientación estratégica que se pretende desarrollar. Además, con una visión integral del conjunto que de las transformaciones requeridas y de las propuestas, se puede plantear la estrategia de cambio más adecuada, comprobando los posibles impactos sobre los distintos ámbitos organizativos considerados.

El proceso de comunicación y discusión generado con la elaboración de los MOEs resulta clave de cara a implicar a los distintos agentes en el proceso de cambio que se pretende impulsar en la organización. La fase final del proceso da lugar a una negociación en la que los diferentes agentes llegan a un acuerdo sobre el modelo de orientación estratégica a desarrollar, que frecuentemente no coincide plenamente con ninguno de los MOEs definidos, sino con una combinación de varios de ellos, aunque siempre aproximándose a uno de los escenarios definidos.

A partir de la opción seleccionada se inicia el proceso de diseño de la estrategia más adecuada para realizar el paso de la situación actual al escenario definido, pero además se dispone de un referente conceptual contra el que poder contrastar las diferentes transformaciones que se propongan de cara a valorar su oportunidad, su coherencia y viabilidad desde una visión integral y estratégica de la organización.

\section{Experiencias de diseño e implementación de Modelos de Orientación Estratégica (MOEs)}

En este apartado se recogen tres experiencias concretas den- tro de la Administración pública en las que se ha desarrollado e implementado la técnica de los MOEs para la definición de sus líneas de desarrollo estratégico en el ámbito organizativo. Los tres casos objeto de estudio son ${ }^{1}$ :

- Un Instituto de Estadística de una Comunidad Autónoma con unos elevados niveles competenciales.

- Una red de oficinas de recaudación tributaria de una Diputación Foral.

- Una Dirección General de Deportes de una Comunidad Autónoma con unos elevados niveles competenciales.

Para cada uno de los tres estudios de caso se presentan las variables que se han considerado relevantes para definir los escenarios de desarrollo organizativo y los MOEs que se asocian a cada uno de dichos escenarios. Para el caso del Instituto de Estadística se incluyen además los configuradores estratégicos (CEOs) que se utilizaron para concretar los modelos de orientación estratégica definidos.

\subsection{La aplicación de los MOEs al desarrollo estratégico de un Instituto de Estadística de una Comunidad Autónoma}

El Instituto de Estadística, adscrito a la Consejería de Economía, tiene como misión genérica promocionar y ofrecer información estadística a los diferentes organismos de su Administración autonómica, al resto de instituciones públicas y a la sociedad de esta Autonomía. Para ello desarrolla tanto la producción estadística propia como la coordinación de las estadísticas públicas producidas a través de un denominado Sistema Estadístico (que integra básicamente a las unidades productoras de las Consejerías y de los distintos organismos de la Administración autonómica).

Después de diversos cambios en la dirección del Instituto, el equipo directivo optó por desarrollar un estudio de dirección estratégica que permitiese adecuar su organización a la misión que tenía encomendada. Para ello se elaboró un estudio cuya primera parte incluía la definición de los MOEs en base a la definición de tres escenarios de futuro.

Después de realizar un diagnóstico de situación (a partir de una metodología que combinaba el análisis documental con la realización de entrevistas y reuniones de grupo a diferentes agentes tanto del propio Instituto como del Sistema Estadístico y clientes externos - actuales y potenciales-), se tomó como variable clave la orientación de la actividad del Instituto de Estadística, distinguiendo como valores extremos la actividad orientada a los productos/servicios de apoyo y de carácter interno (unidades productoras de estadísticas de la Administración de la Comunidad Autónoma) y la actividad orientada a la producción directa de estadísticas para los grupos objetivo (básicamente exter- 
Gratico 2

Definición de escenarios y MOEs para el Instituto de Estadística

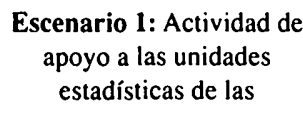

Consejerías de la CA

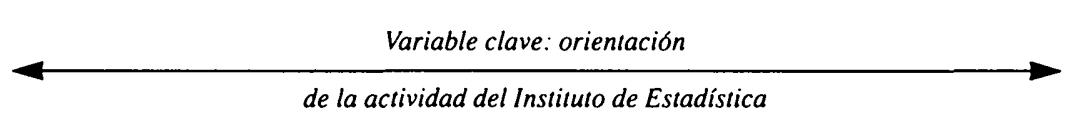

Escenario 2: Actividad

orientada a producir

estadísticas para la

sociedad de la Autonomía

\section{MODELODE \\ ORIENTACIÓN \\ INTERNA}

Fuente: Elaboración propia. nos). Aunque el modelo real debe combinar, obviamente, ambas dimensiones, lo que se pretende destacar con esta variable son las implicaciones de optar claramente por una orientación u otra.

A través de la definición y concreción de ambos factores se configuran los parámetros esenciales de la estrategia de desarrollo de la organización, a partir de la cual diseñar los Modelos de Orientación Estratégica.

\subsubsection{Los MOEs del Instituto de Estadística}

Para presentar el esquema de la propuesta de orientación estratégica del IE se definen tres modelos de desarrollo organizativo que responden, respectivamente, a tres hipotéticos escenarios de futuro. En tanto que modelos ideales (es decir, no reales) cada uno de ellos recoge las variables definidoras del IE ante tres estrategias de desarrollo diferenciadas. Su valoración y discusión conjunta permite ofrecer una imagen de las tendencias orientadoras del modelo, o combinación de modelos, por el que se opte en última instancia.

\section{El Modelo Continuista}

El planteamiento de orientación estratégica en que se basa el Modelo Continuista se caracteriza por, paradójicamente, prescindir de un modelo claro de orientación. La definición de los elementos clave de la estrategia de la organización viene determinada por las inercias ya iniciadas en la etapa actual de desarrollo, sin imprimir un direccionamiento claro sobre ellas ni prever hacia dónde conducen. En tanto que modelo ideal, propuesto para su discusión, en el siguiente planteamiento sólo se han detallado los posibles problemas derivados de las mencionadas inercias.
Su orientación hacia productos y servicios viene dominada por el predominio de la lógica de producción, aunque sin plan. tearse claramente qué o para quién se produce, o si se produce lo que se debe. En su orientación estratégica hacia los grupos objetivo el elemento destacado es la dispersión, tanto en relación a los actores internos como externos, aunque con cierto predominio de estos últimos. Los mecanismos para dirigirse a ambos colectivos se basan en el envío masivo de publicaciones con recopilaciones estadísticas, sin desarrollar una reflexión clara de hacia quién se dirigen ni cómo se elaboran para que sean útiles para los hipotéticos usuarios finales.

En relación a las variables organizativas y de configuración estructural, el Modelo Continuista se caracteriza por tender a la desmotivación del personal, que presenta niveles formativos desiguales, sin capacidad para desarrollar estrategias de aprendizaje organizativo. Se define un sistema con una clara visión departamental y no horizontal, sin capacidad de coordinación de unas unidades estadísticas no consolidadas en sus respectivas Consejerías. La actividad viene presidida por un carácter reactivo, de orientación dispersa hacia el exterior.

\section{El Modelo de Orientación Interna}

La principal característica del Modelo de Orientación Interna es su orientación hacia el resto de la Administración autonómica, tanto a nivel de producción y elaboración estadística como en la prestación de servicios de apoyo interno a la producción y análisis que se realiza en otras unidades. En la estrategia de desarrollo el elemento clave es la capacidad de aportar valor en la actividad desarrollada tanto en los servicios de apoyo como en la producción estadística para uso interno.

En la orientación hacia productos/servicios el elemento clave es la capacidad de aportar valor, de crear valor en la actividad 
desarrollada tanto en los servicios de apoyo como en la producción estadística para uso interno. En concreto se trata de superar la mera confección de estadísticas o.programación de cursos de formación o de facilitar un software estadístico para entrar a conocer las verdaderas necesidades y oportunidades que se plantean en relación a la actividad desarrollada por los usuarios de los productos y servicios, y ser capaces de satisfacerlas desde el IE.

Otro elemento esencial que se desprende del desarrollo de esta estrategia a medio y largo plazo es la configuración de un protagonismo de perfil bajo o indirecto para el IE. Puesto que el factor clave de éxito no es tanto conseguir un prestigio propio desde el exterior, sino ser conocido e imprescindible para los verdaderos usuarios efectivos de la estadística, tanto a nivel de producción (imprescindible prestando servicios de apoyo) como de análisis (imprescindible facilitando las estadísticas concretas). Se trata de conseguir el éxito y legitimarse en la medida que se es imprescindible y no tanto por ser más o menos conocido en el exterior, dejando el protagonismo en manos de los clientes, como una parte del valor añadido que se ofrece en los servicios y productos que se prestan desde el IE.

En relación a los Configuradores Organizativos (CEOs), el Modelo de Orientación Interna se caracteriza por una estructura y personal orientado a prestar servicios a las unidades de la Administración de la Comunidad Autónoma, a partir de la configuración de un sistema más flexible en el que las unidades estadísticas se consolidan vinculadas a los órganos transversales de las Consejerías. Su actividad presenta un estilo proactivo, atento a las necesidades de sus clientes internos, ofreciendo una visión de la estadística como información (datos con intencionalidad), potenciando una imagen de independencia, aunque sin enfatizar su protagonismo. Se define así un IE consolidado con una pluralidad de apoyos internos, integrador de los sistemas de información de la Administración autonómica, con un liderazgo concebido más sobre la creación de valor que sobre el protagonismo directo hacia el exterior:

\section{El Modelo de Orientación Externa}

En contraposición al anterior, el elemento clave del Modelo de Orientación Externa es su orientación hacia el exterior, basando su legitimación en la producción y difusión de servicios estadísticos a clientes y usuarios externos a la Administración autonómica.

En este modelo, la orientación hacia productos/servicios vendría presidida por la difusión externa, con el apoyo de la producción propia y la producción del resto del Sistema Estadístico. Un elemento clave es la definición de productos atractivos al mercado, que permitan crear grupos estables de demanda a diferentes niveles (desde niveles directivos públicos y privados a las actividades de pedagogía en escuelas y universidades, por poner tan sólo dos ejemplos). En relación a los grupos objetivo se plantea la orientación clara hacia un colectivo de clientes externos claramente definidos, creando una red externa alternativa que sustituya la red de interlocutores internos que se creaba con el modelo de orientación interna. La orientación hacia el Sistema Estadístico se basa en un juego de intereses en los que el objetivo del IE es conseguir información que le permita mantener unas líneas de difusión propias. El resultado asociado a este modelo es la adopción de un protagonismo de perfil alto o directo, con el que el IE adquiere una legitimidad propia por la vía externa a la Administración autonómica.

En cuanto a las variables organizativas, este modelo se caracteriza por disponer de un personal orientado a la comunicación con clientes externos, cobrando especial importancia el área de difusión con criterios de marketing que tiendan a configurar una demanda externa. A nivel de sistema, se potencian las unidades productoras de estadísticas como fuente de recursos para su posterior difusión externa. El estilo proactivo de cara al exterior se complementa con un enfoque participativo, que integra a los clientes de cara a establecer redes estables de relación externa. La estrategia potencia la producción de estadísticas a medida de los clientes externos, ofreciendo una imagen de rigor e independencia en la que el IE adopta el protagonismo de agente integrador de la difusión estadística de la Administración autonómica.

\subsubsection{Los Configuradores Estratégicos de la Organización}

La concreción y las implicaciones de los tres modelos de orientación estratégica, en el plano organizativo, se definen a partir de los Configuradores Estratégicos de la Organización (CEOs). A partir del diagnóstico de situación y el análisis estratégico presentado, se consideran los siguientes $C E O$ s relevantes para definir cada modelo: estrategia, estilo, sistema, estructura y personal.

\subsection{La aplicación de los MOEs al desarrollo estratégico de las Oficinas Tributarias de una Diputación Foral}

Las Oficinas Tributarias, adscritas al Departamento de Hacienda y Finanzas de la Diputación Foral, son las encargadas de la recaudación ejecutiva, que se dirige a cobrar aquellos importes no abonados por el contribuyente durante el período voluntario de pago (en relación a todos los impuestos gestionados por la Diputación y abarcando todo el territorio de la provincia). 


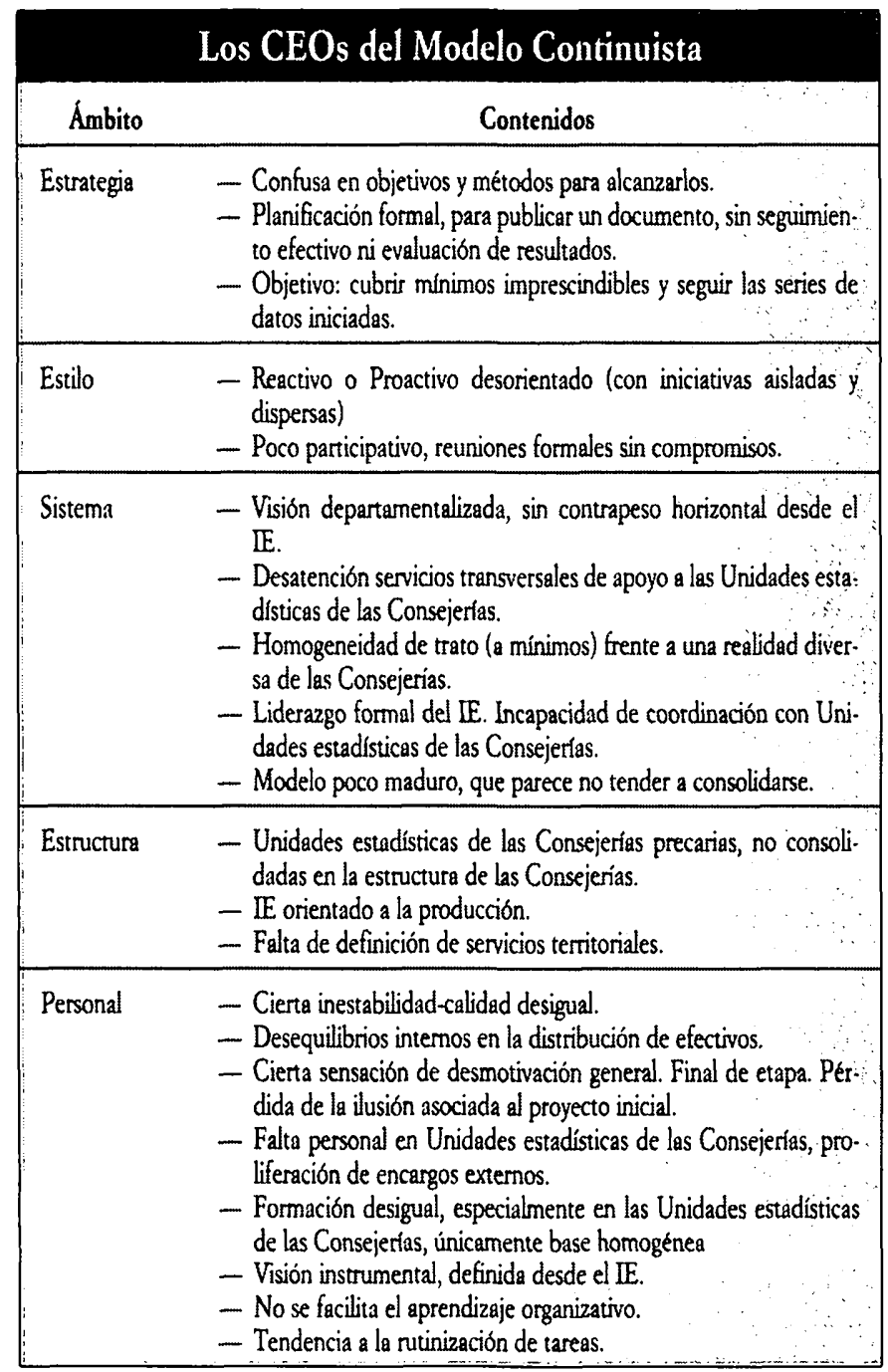

En el marco de un proceso de rediseño organizativo que afectaba tanto a la estructura orgánica como a ciertos procedimientos de actuación, se planteó la necesidad de realizar un estudio que permitiese adecuar los cambios a desarrollar con una orientación estratégica global y coherente con una perspectiva más a largo plazo. Con ese objetivo se introdujo la identificación de los MOEs en base a la definición de tres escenarios de futuro.

Después de realizar un diagnóstico de situación, que también sirvió de base a la realización de los informes referidos a la estructura y a los procedimientos, se consideraron dos variables clave para la definición de los escenarios de desarrollo organizativo. La primera variable se refiere al grado de descentralización organizativa para el desarrollo de la actividad recaudatoria. La segunda se sitúa en el plano del desarrollo de la actividad a través de la propia organización (toda la actividad la realizan exclusivamente unidades de la propia Diputación Foral), frente a la opción de desarrollarla a través de una red externa de organizaciones (incorporando desde enti-

\begin{tabular}{|c|c|}
\hline Ámbito & dos \\
\hline Estrategia & $\begin{array}{l}\text { - Sistemas de Información como OPORTUNIDAD. Visión de la } \\
\text { estadistica como información (datos con intencionalidad). } \\
\text { - Potenciar las estadisticas aplicadas a la gestión. } \\
\text { - Potenciar el rol (y la imagen) de rigor e independencia del IE. } \\
\text { Sin poner el énfasis en el protagonismo del propio IE. }\end{array}$ \\
\hline Estilo & $\begin{array}{l}\text { - Proactivo de cara al resto de la Administración autonómica. Dar } \\
\text { respuestas a las demandas externas, pero no crearlas. } \\
\text { - Estilo participativo, tanto en la relación con Unidades estadisticas } \\
\text { de las Consejerias como internamente en el IE. } \\
\text { - Estilo participativo con clientes de la Comunidad Autónoma } \\
\text { (Gabinetes de Consejerías, órganos de staff, apoyo técnico). }\end{array}$ \\
\hline Sistema & $\begin{array}{l}\text { - Segmentación de la clientela: diferente trato a Consejerfas con } \\
\text { diferentes particularidades. Relaciones bis a bis. } \\
\text { - Potenciación de los contactos tanto a nivel formal como a nivel } \\
\text { informal. } \\
\text { - IE como coordinador y prestador de servicios horizontales (le. } \\
\text { gitimidad a medio y largo plazo). } \\
\text { - Atribución clara de responsabilidades en el IE para la gestión } \\
\text { del Sistema Estadístico (con idea clara de su rol y de la estrategia } \\
\text { global). } \\
\text { - Descentralización máxima de la producción. }\end{array}$ \\
\hline Estructura & $\begin{array}{l}\text { - Consolidación de las Unidades estadísticas de las Consejerfas, } \\
\text { vinculadas a Viceconsejerías (órganos transversales de senvicios } \\
\text { a la Consejería). } \\
\text { - Redimensionamiento interno del IE: mayor peso de las áreas } \\
\text { de difusión (interna) y de coordinación. } \\
\text { - Incorporación de la gestión por proyectos. }\end{array}$ \\
\hline Personal & $\begin{array}{l}\text { - Estable - Cambiar inestabilidad por un sistema más flexible (ges. } \\
\text { tión por proyectos). } \\
\text { - Personal reubicable internamente en función de necesidades } \\
\text { puntuales. } \\
\text { - Restringir el sistema de becarios - estabilizar profesionales de } \\
\text { la materia. } \\
\text { - Redistribución interna de efectivos en el IE. Porenciación del } \\
\text { área de Difusión pero con carácter interno. } \\
\text { - Difusión interna/Comunicación transversal. } \\
\text { - Técnicas de gestión de las redes del sistema. } \\
\text { - Coordinación con unidades productoras (además de con las Uni- } \\
\text { dades estadisticas de las Consejerias). } \\
\text { - IE como gestor de un sistema de información integralgestor } \\
\text { de una red de productores y consumidores de estadisticas. } \\
\text { - Adaptación a nuevas demandas y perfiles de usuarios. } \\
\text { - Aprendizaje organizativo y Planificación de la formación en con. } \\
\text { cordancia con la estrategia de la organización. }\end{array}$ \\
\hline
\end{tabular}

dades financieras a ayuntamientos en la realización de la actividad recaudatoria). A través de la combinación de ambas variables se configuran cuatro escenarios básicos de desarrollo organizativo, a partir de los cuales definir los Modelos de Orientación Estratégica.

Al presentar la proyección futura de las Oficinas Tributarias se plantea la discusión de sus elementos configuradores actuales y su posible evolución, con el objetivo de trazar las grandes líneas definidoras de los escenarios de futuro. A partir de la conceptualización de éstos se pretende facilitar el diseño anti- 


\section{Los CEOs del Modelo de Orientación Externa}

\begin{tabular}{|c|c|}
\hline Ámbito & Contenidos \\
\hline Estrategia & $\begin{array}{l}\text { - Producción de estadísticas actualizadas (estadísticas al minuto) } \\
\text { como oportunidad para dinamizar el IE. } \\
\text { - Potenciar las estadísticas aplicadas de utilización externa, dis- } \\
\text { tinguiendo clientes por perfles. } \\
\text { - Potenciar el rol (y la imagen) de rigor e independencia del IE, } \\
\text { poniendo énfasis en el protagonismo directo del IE. }\end{array}$ \\
\hline Estido & $\begin{array}{l}\text { - Prouctivo de cara al exterior. Crear y cubrir demanda externa } \\
\text { como vía legitimadora del IE (nivel de conocimiento). } \\
\text { - Estilo participativo internamente en el IE, en la definición de } \\
\text { productos y atención a la demanda. } \\
\text { - Estilo participativo con clientes externos en la definición de pro- } \\
\text { ductos (orientación empresarial). } \\
\text { - Fidelizar clientes. Establecer redes estables de relación externa. }\end{array}$ \\
\hline Sistemu & $\begin{array}{l}\text { - Segmentación de la clientela externa: definición de perfiles de } \\
\text { clientes y de necesidades estadísticas. } \\
\text { - Potenciación de los contactos y de las interfaces de relación con } \\
\text { el exterior. } \\
\text { - IE como coordinador y prestador de servicios verricales, hacia } \\
\text { el exterior (impacto a corto plazo). } \\
\text { - Gabinete Técnico del IE como gestor del Sistema Estadistico } \\
\text { (orientado a la vigilancia y control de la calidad estadística de } \\
\text { cara a su oferta hacia el exterior). } \\
\text { - Centralización/descentralización máxima de la producción pero } \\
\text { centralización de la difusión. }\end{array}$ \\
\hline Estructura & $\begin{array}{l}\text { - No se consolidan las Unidades estadísticas de las Consejerias, } \\
\text { pero se atiende especialmente a las productoras. } \\
\text { - Redimensionamiento interno del IE: mayor peso de las áreas } \\
\text { de difusión (externa) y de una unidad de comunicación. }\end{array}$ \\
\hline Personal & $\begin{array}{l}\text { - Flexible, perfil orientado a la comunicación con clientes externos } \\
\text { (gestión por proyectos). } \\
\text { - Personal reubicable internamente en función de necesidades } \\
\text { puntuales, con campañas concretas en respuesta a demandas } \\
\text { externas. } \\
\text { - Redistribución interna de efectivos en el IE. Potenciación del } \\
\text { área de Difusión (y comunicación) pero con carácter externo. } \\
\text { - Difusión externa/Comunicación con agentes externos, a diferen- } \\
\text { tes niveles. } \\
\text { - Marketing de servicios y definición de productos de cara a la } \\
\text { configuración de la demanda. Gestión de la calidad de servicio. } \\
\text { - Adaptación a nuevas demandas y perfiles de usuarios. } \\
\text { - Courdinación con unidades productoras (además de con las Uni- } \\
\text { dades estadísticas de las Consejerfas), pero centralización } \\
\text { - - } \text {-monopoliom de la difusión hacia el exterior. } \\
\text { - IE como gestor de un sistema de estadísticas integral/gestor de } \\
\text { una red de productores y consumidores de estadísticas. } \\
\text { - Aprendizaje del exterior y Planificación de la formación en con- } \\
\text { cordancia con la estrategia de la organización. }\end{array}$ \\
\hline
\end{tabular}

cipativo de aquellos elementos propios de la organización para facilitar su adaptación al cambio.

Al plantear las opciones que se desarrollan a continuación se parte de la selección de dos ejes de definición de escenarios, considerando que son los que aportan un mayor contenido explicativo del desarrollo prospectivo de las unidades de recaudación, aun admitiendo la existencia de dimensiones alternativas que no se abordarán en este análisis introductorio.
A partir de la combinación de las líneas de centralización/descentralización y desarrollo propio/desarrollo en red, se plantean cuatro modelos de configuración estratégica. Estos cuatro modelos no corresponden a ninguna configuración real, sino que deben considerarse como tipos ideales hacia los que se aproximan los modelos reales. Su valoración y discusión conjunta permite ofrecer una imagen de las tendencias orientadoras del modelo o combinación de modelos por el que se opte en última instancia.

\subsubsection{Los MOEs de las Oficinas Tributarias de la Diputación Foral}

Para presentar el esquema de la propuesta de orientación estratégica de las Oficinas Tributarias se han definido cinco modelos de desarrollo organizativo que responden, respectivamente, a cinco hipotéticos escenarios de futuro. En tanto que modelos ideales (es decir, no reales), cada uno de ellos recoge las variables definidoras de las Oficinas Tributarias ante cinco estrategias de desarrollo diferenciadas. Su valoración y discusión conjunta permite ofrecer una imagen de las tendencias orientadoras del modelo, o combinación de modelos, por el que se opte en última instancia.

A partir de las variables clave definidas, los Modelos de Orientación Estratégica que se plantean en relación al desarrollo organizativo de las Oficinas Tributarias son (Gráfico 4):

\section{El Modelo Incremental o Continuista}

El planteamiento de orientación estratégica en que se basa el modelo continuista se caracteriza por prescindir de un modelo claro de orientación. La definición de los elementos clave de la estrategia de la organización viene determinada por las inercias ya iniciadas en la etapa actual de desarrollo, sin imprimir un direccionamiento claro sobre ellas ni prever hacia dónde conducen.

Este modelo de desarrollo parte de considerar la ausencia de cambio en la estrategia de las Oficinas Tributarias, es decir, que prolonga hacia el futuro las inercias iniciadas en la actualidad sin que se incorpore una lógica clarificadora o se inicie una nueva etapa en la definición de estas organizaciones. Así, su principal característica sería la no existencia de una estrategia de desarrollo. Sus principales características definidoras se presentan en el apartado referido a los Configuradores Estratégicos de la Organización. 


\section{Gráfico 3}

\section{Definición de escenarios y MOEs para las Oficinas Tributarias de la Diputación Foral}

Variable 1:

Desarrollo a través de la

propia organización

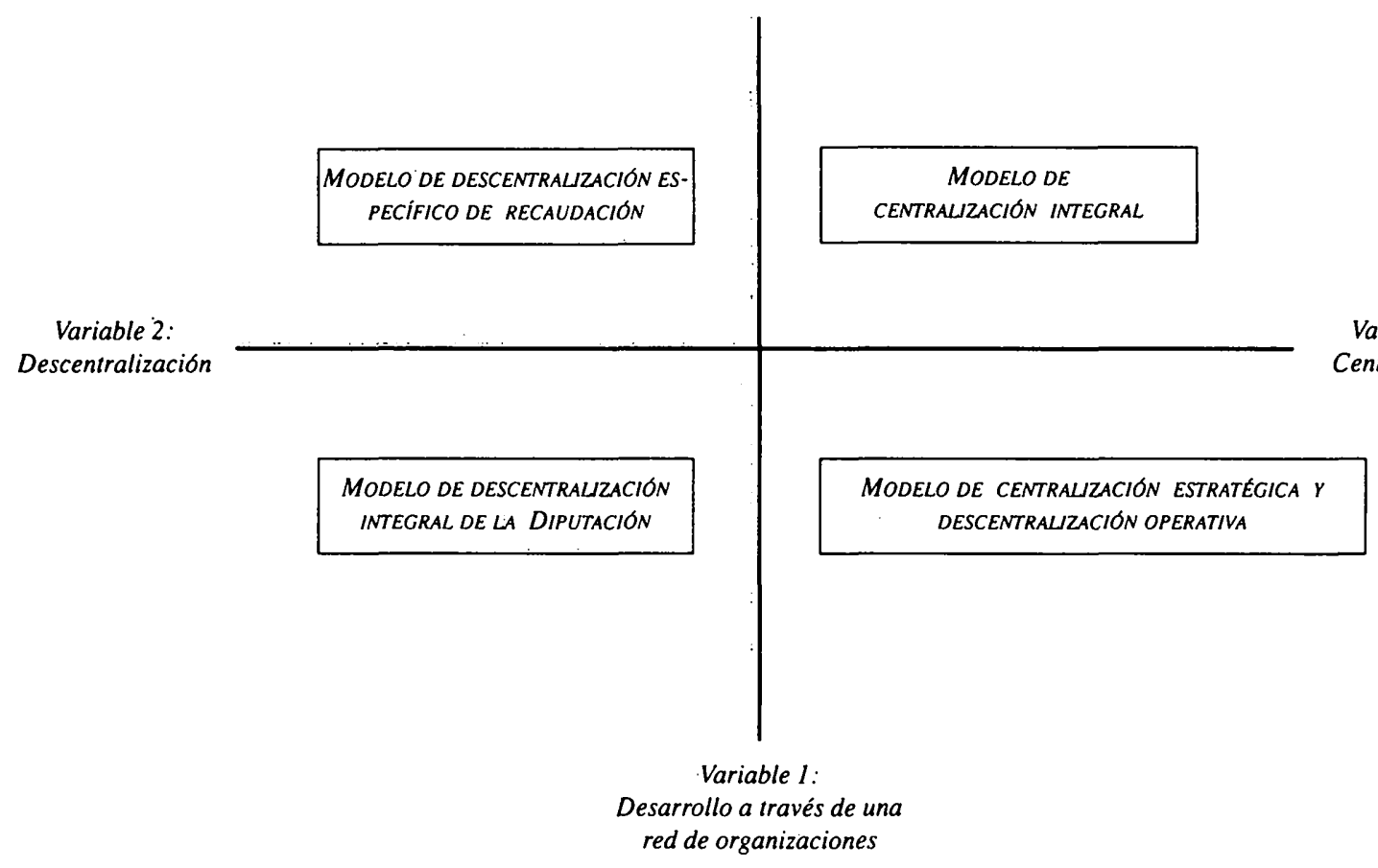

Variable 2:

Centralización

Fuente: Elaboración propia.

\section{Los Modelos Descentralizados}

A partir del modelo de acercamiento al ciudadano que se propuso como uno de los ejes clave de la política de la Diputación Foral, como premisa clave del proceso de descentralización de las Oficinas Tributarias, se plantea la continuación de esa línea, aunque introduciendo un enfoque de orientación estratégica en el modelo a desarrollar. Se concebiría así un modelo de organización renovada y potenciada: mejora de las condiciones organizativas en su funcionamiento, redefinición de los territorios y de la ubicación de las Oficinas y redefinición del rol de los servicios centrales. Esta dimensión, combinada con la variable de realización de la actividad a través de la propia organización o a través de una red de organizaciones, da lugar a dos modelos de orientación estratégica:

\section{MOE 1: El Modelo descentralizado, especifico de recaudación}

A partir del modelo actual basado en Oficinas Tributarias, esta primera acepción del modelo descentralizado tendería a mejorar los parámetros de funcionamiento sin modificar la distribución global de funciones asignadas a las unidades descentralizadas. La reasignación de tareas específicas o colectivos de deudores no implicaría una reestructuración rupturista con las dinámicas iniciadas en estos momentos.

\section{MOE 2: El Modelo descentralizado, integral de la Diputación Foral}

Este modelo se refiere a la inclusión en el proceso de descentralización a los demás servicios de la Diputación, pero no de forma diferenciada, sino integrándolos en un mismo proyecto común.

La Diputación Foral opta por descentralizar buena parte de sus Departamentos y servicios y crear unas oficinas territoriales de gestión unificada. Para ello se deben definir unas nuevas unidades territoriales y los núcleos de población donde se van a ubicar los servicios centrales. ¿Saldrían beneficiadas con esta estrategia las Oficinas Tributarias? Probablemente sí; por una parte, se beneficiarian de la economía de escalas y, por otra, los servicios centrales de la Diputación serían conscientes de los costes y problemas de un modelo descentralizado. A nivel de imagen corporativa se asocian, a la vista del contribuyente, las funciones de recaudación y de gasto, es decir, el contribuyente asociaría más el dinero que paga con algunos de los servicios que percibe (aunque ello debería contrastarse con el 


\section{Gréfico 4}

\section{Esquema de la exposición de los MOEs para las Oficinas Tributarias de la Diputación Foral}

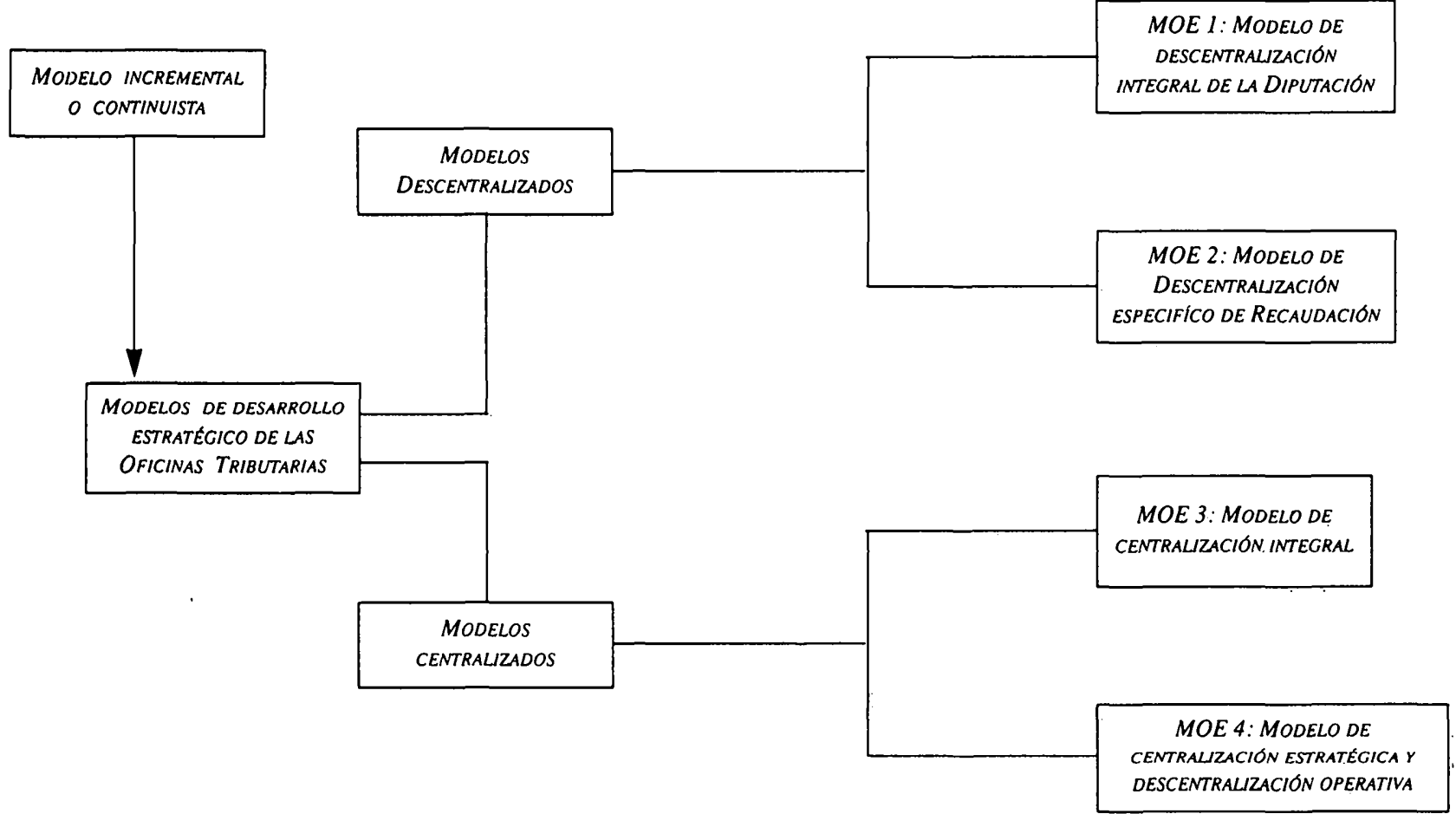

Fuente: Elaboración propia.

hecho de que no todo lo que recauda la Diputación va hacia sus servicios, sino que una parte importante es transferida a otros niveles de gobierno).

\section{Los Modelos centralizados}

8

Estos modelos parten de una redefinición drástica de la estrategia de desarrollo de las Oficinas Tributarias: cierre de las oficinas y agencias tributarias y asunción de sus funciones por parte de los servicios centrales. Estos modelos pondrían el énfasis en el desarrollo de economías de escala a través de la mejora de los mecanismos para dirigirse al ciudadano desde una unidad central. Esta macrounidad se encargaría de todos los procesos que actualmente desarrollan las Oficinas y daría continuidad a las funciones ya desarrolladas en los servicios centrales.

\section{MOE 3: El Modelo de centralización integral}

Los rasgos distintivos de este modelo se orientan a acentuar la centralización tanto de funciones de carácter estratégico como las de carácter operativo. Partiendo de esa concepción, el esfuerzo principal se orientaría a aprovechar al máximo los canales habituales de relación con el público para dirigirse a los contribuyentes. Campañas de información a través de los medios de comunicación, un importante servicio telefónico con líneas «calientes», la comunicación a través de correos y otros canales de acercamiento de la información y la gestión a los ciudadanos.

\section{MOE 4: El Modelo de centralización estratégica $y$ de descentralización operativa}

A partir del modelo centralizado como eje básico, esta acepción se orientaría a la descentralización de aquellas tareas de carácter operativo que facilitan el contacto entre la Administración y el ciudadano. A través de convenios con instituciones intermedias (como Ayuntamientos, entidades bancarias u otros agentes similares) se descentralizarían las funciones de carácter más general como el caso de la transmisión de la información básica o la recepción y entrega de documentos, entre otras, dejando abierto un canal fluido de comunicación entre estos agentes y la unidad central. Se mantendrian a nivel de unidad central aquellas funciones de carácter más estratégico y las que impliquen mayores grados de dificultad. Dentro de este modelo 


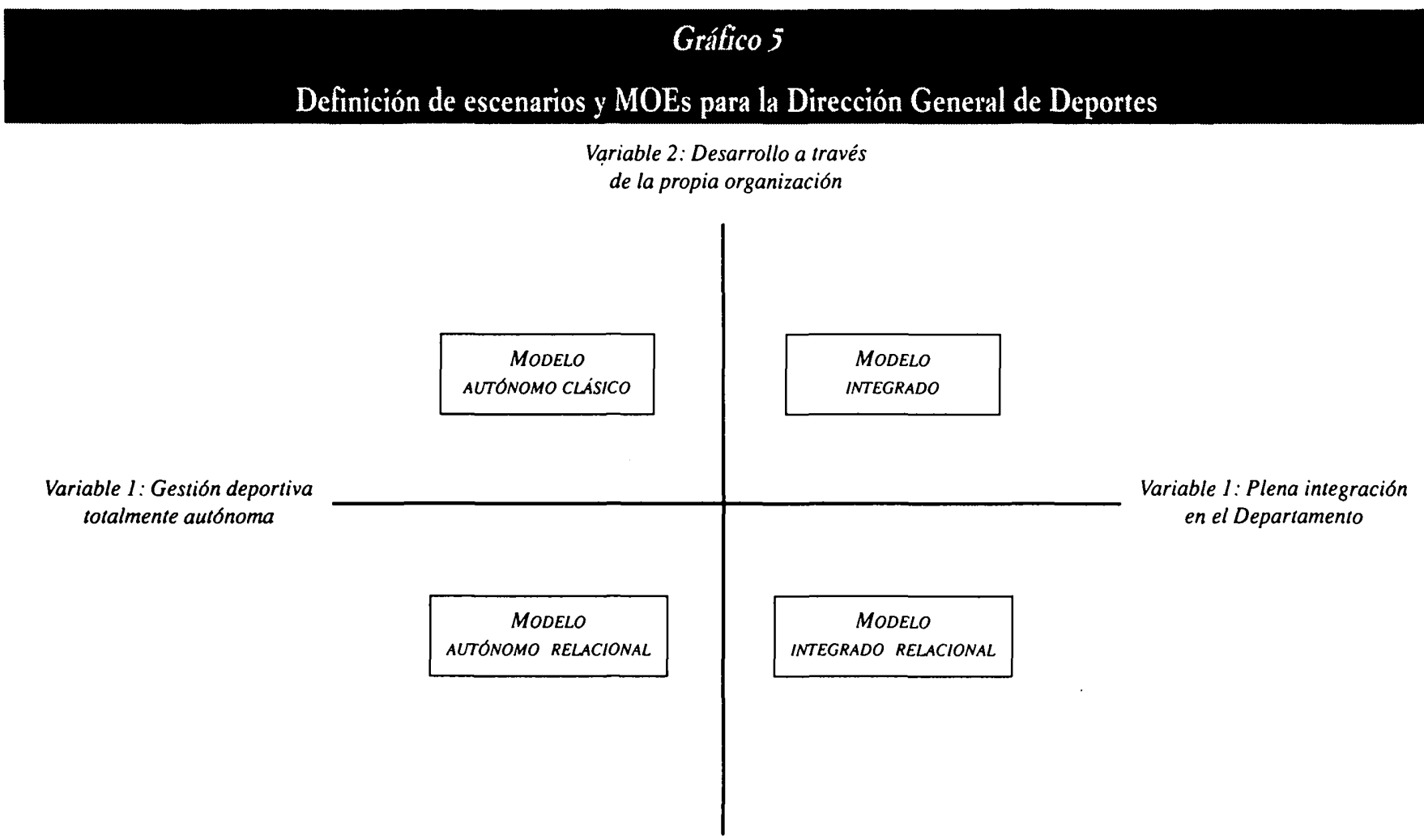

Variable 2: Desarrollo a través

de una red de organizaciones

Fuente: Elaboración propia.

se establece una gradación de niveles de externalización de servicios que variaría desde la prestación de los servicios de atención a un primer nivel (información y atención al público) a la privatización de la actividad recaudadora (tal y como se daba en la situación anterior de las encomiendas).

\subsection{La aplicación de los MOEs al desarrollo estratégico de la Dirección General de Deportes de una Comunidad Autónoma}

La Dirección General de Deportes, adscrita al Departamento de Cultura de la Comunidad Autónoma, tiene por misión la promoción del deporte, tanto a nivel profesional como en tanto que actividad cultural y de ocio, y tanto a través de la formación y preparación de deportistas como mediante la promoción de asociaciones y clubes deportivos que fomenten esta actividad en el seno de la sociedad.

A partir de un cambio en la estructura directiva de la Dirección General de Deportes se propuso la elaboración de un estudio organizativo, a partir del cual introducir diversas transformaciones encaminadas a preparar la organización a un entorno en el que los agentes sociales asumían un protagonismo cada vez mayor. Para ello, y de cara a facilitar el desarrollo de una orientación estratégica global y una perspectiva más a largo plazo, se optó por realizar una definición de los diferentes MOEs que surgían a partir de la consideración de las variables clave para dicha organización.

Con posterioridad a la realización de un diagnóstico de situación, se tomaron dos variables clave para definir los escenarios de desarrollo organizativo de la Dirección General de Deportes. La primera variable considerada se refiere al nivel de autonomía/integración de la Dirección General en relación al Departamento de Cultura al cual está adscrita orgánicamente, con vistas a la posible creación de un organismo autónomo. En esta variable se establece un eje dicotómico a partir del cual se definen dos escenarios extremos - en el sentido de ideales/radicales-: el extremo de autonomía total de la Dirección General, en que ésta actuaría como un organismo autónomo (lo que implicaría la autogestión a nivel económico, de personal, etc.), y el extremo de la plena integración al Departamento, en el que la unidad actuaría como una Dirección General más (lo que supondría que la gestión de sus servicios internos estaría a cargo de la Secretaría General del Departamento como unidad responsable de la gestión de los servicios comunes). Aunque la opción final integre elementos de ambos escenarios, en rea- 
lidad existirá el predominio de uno en cuanto a las relaciones entre la Dirección General y el Departamento.

La segunda variable considerada se refiere a la configuración estructural a través de la cual se lleva a cabo la actividad que realiza la Dirección General de Deportes, diferenciando un desarrollo a través de la propia organización de la opción por desarrollar la actividad a través de una red externa de organizaciones (ya sean públicas o privadas). Con esta segunda variable se recoge el dilema cada vez más presente en la definición de los estilos de actuación de las Administraciones públicas, distinguiendo la prestación de servicios a través de grandes estructuras públicas y la prestación de servicios mediante constelaciones de organizaciones vinculadas a un reducido núcleo administrativo que lleva a cabo las funciones de carácter más estratégico y externaliza las de carácter administrativo.

A partir de la combinación de las variables autonomía/integración y desarrollo a través de la propia organización/desarrollo a través de una red de organizaciones, se definen cuatro MOEs que, por su carácter ideal y no real, permiten ofrecer una imagen de las tendencias orientadoras del modelo, o de la combinación de modelos, sobre los que se plantea optar de cara a configurar una orientación estratégica en el ámbito organizativo.

\subsubsection{Los MOEs de la Dirección General de Deportes}

Para presentar el esquema de la propuesta de orientación estratégica de la Dirección General de Deportes de la Comunidad Autónoma se han definido cuatro modelos de desarrollo organizativo que responden, respectivamente, a cuatro hipotéticos escenarios de futuro. En tanto que modelos ideales (es decir, no reales) cada uno de ellos recoge las variables definidoras de la Dirección General de Deportes ante cuatro estrategias de desarrollo diferenciadas. Su valoración y discusión conjunta permite ofrecer una imagen de las tendencias orientadoras del modelo, o combinación de modelos, por el que se opte en última instancia.

A partir de las variables clave definidas, los modelos de orientación estratégica que se plantean en relación al desarrollo organizativo de la Dirección General de Deportes son:

\section{Grítico 6}

\section{Esquema de la exposición de los MOEs para la Dirección General de Deportes}

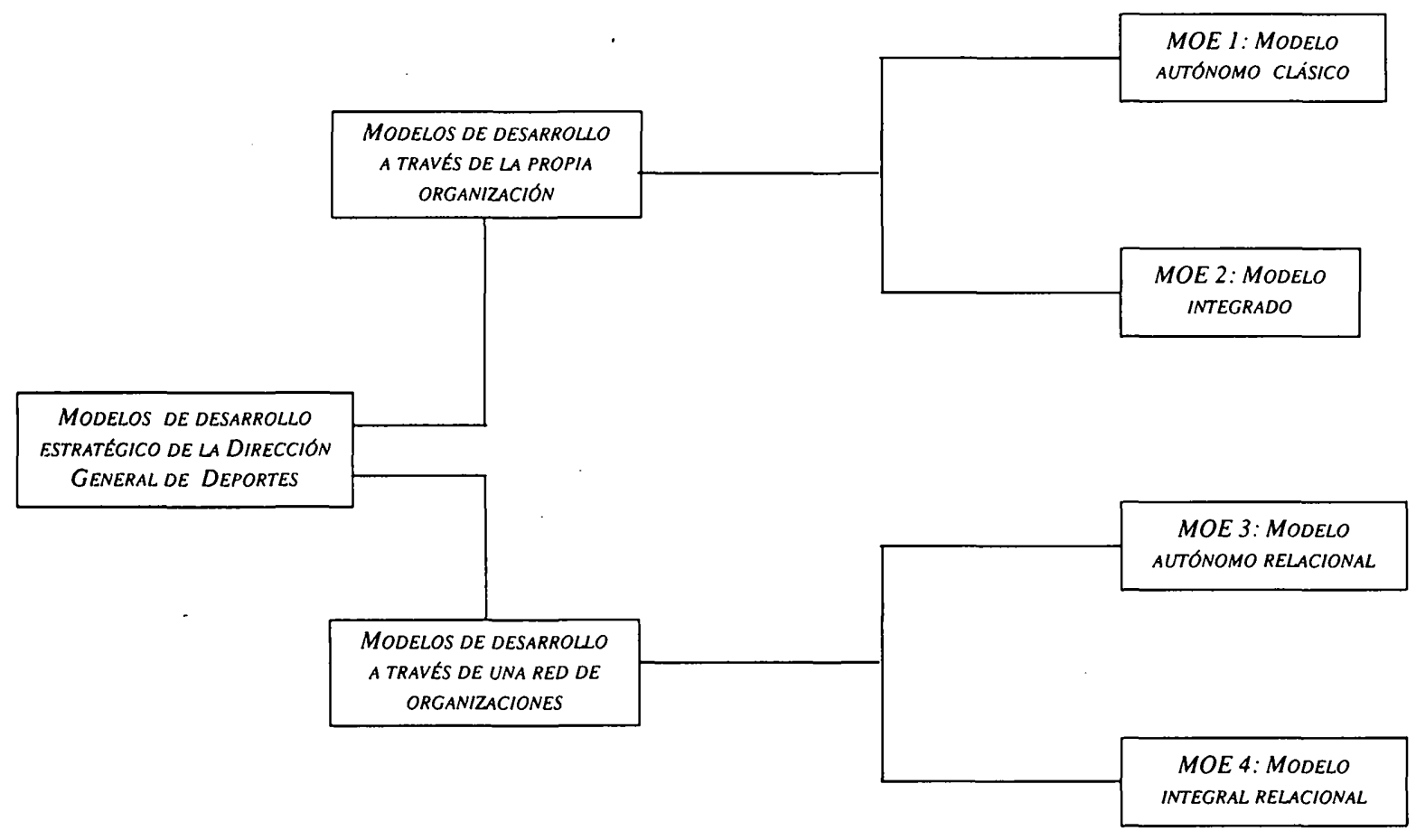

Fuente: Elaboración propia. 


\section{Modelos de desarrollo a través de la propia organización}

Los dos primeros modelos considerados tienen en común el hecho de desarrollar su actividad a través de la propia organización, es decir, sin crear un sistema de organizaciones externas (ya sean públicas o privadas) relacionadas con la Dirección General de Deportes. Cabe destacar que, en el plano ideal en el que se definen los modelos, los que se vinculan a esta variable tienden a desplegar una organización basada primordialmente en clientes y, en menor medida, en funciones. A partir de la primera variable considerada (nivel de autonomíaintegración en el Departamento de Cultura), se distinguen dos modelos:

\section{MOE 1: El Modelo Autónomo Clásico}

Este modelo se caracteriza por disponer de una estructura que recoge todas las funciones de apoyo interno a la actividad (personal, compras y contratación, gestión económica), que se desarrollaría con un amplio margen de maniobra, con una formulación propia de un organismo autónomo.

A través de este mayor despliegue de la estructura y de los recursos humanos (puesto que no se producen economías de escala con la estructura del Departamento al que está adscrita la Dirección General de Deportes), vinculado a una dinámica de funcionamiento totalmente autónoma de consignas departamentales, la Dirección General de Deportes dispondría de un amplio margen para definir los aspectos clave de la implementación operativa de sus políticas concretas. Precisamente, el desarrollo a través de la propia organización supone que todas las actividades desarrolladas por la Dirección General de Deportes serían implementadas mediante recursos propios, amparada en el carácter autónomo para adecuarse a la variabilidad del entorno en el que actúa.

\section{MOE 2: El Modelo Integrado}

A diferencia del modelo anterior, en este caso la organización de la Dirección General de Deportes se integraría totalmente en los parámetros de funcionamiento del Departamento de Cultura. Esta plena integración supondría la práctica eliminación de los servicios de apoyo interno a la actividad desarrollada, sustituidos por los ya existentes en el Departamento, así como la aparición de importantes economías de escala en otro tipo de funciones desarrolladas también por otras unidades adscritas a Cultura. Funciones como la gestión de personal, la contratación o el apoyo informático, y funciones de apoyo a la actividad desarrollada como el mantenimiento de instalaciones deportivas o el seguimiento contable de las subvenciones otor- gadas entrarían en este conjunto de ámbitos susceptibles de ser compartidos con los servicios existentes en el Departamento.

Por otro lado, se mantendrían las unidades configuradas actualmente para dar apoyo a servicios directos a los diferentes tipos de clientes con los que se relaciona la Dirección General de Deportes, manteniendo así el desarrollo de la actividad a través de la propia organización. La existencia de ciertas rigideces en algunos aspectos del funcionamiento propio de la dinámica de la Administración pública podrían suplirse con contrataciones puntuales de servicios concretos, sin entrar a cuestionar la validez del funcionamiento de la mayor parte de actividades que conforman el núcleo duro de la Dirección General de Deportes.

\section{Modelos de desarrollo a través de una red de organizaciones}

A diferencia de los dos modelos anteriores, en este caso uno de los rasgos definidores es el desarrollo de la actividad propia de la Dirección General de Deportes a través de una constelación de organizaciones, que incluye desde entidades deportivas a empresas privadas vinculadas a la realización de cierto tipo de servicios externalizados. Las estructuras administrativas de los modelos de desarrollo a través de una red de organizaciones tenderían a tomar una orientación funcional más que basada en clientes.

En el plano ideal considerado, esta orientación centrada en las funciones responde al hecho de que la orientación por clientes es la que se da en el conjunto de organizaciones vinculadas a la Dirección General de Deportes, lo que permite a ésta tomar un modelo organizativo más orientado a las funciones a desarrollar. Dentro de este escenario de desarrollo organizativo a través de una red de organizaciones (relacional), se definen dos modelos ideales a partir de la consideración de la variable autono. mía/integración departamental.

\section{MOE 3: El Modelo Autónomo Relacional}

En este modelo la configuración autónoma comentada en el modelo autónomo clásico se complementa con el desarrollo de la actividad a través de una red externa de organizaciones que no forman parte de la Dirección General de Deportes. La dinámica organizativa que supone esta opción combinaría un modelo de externalización de servicios con un modelo de implicación de entidades deportivas en las actividades ligadas a la implementación de políticas y programas diseñados desde la Dirección General de Deportes.

El mantenimiento de una estructura interna que permitiese una dinámica autónoma del Departamento (incluyendo las funciones de gestión de personal, gestión económica, etc.) se combinaría con la necesidad de reciclar aquellas unidades que rea- 
lizan actividades más vinculadas a la implementación de programas, para favorecer su transformación hacia un modelo de Administración habilitadora, en el cual se desarrollan tareas de apoyo, control y seguimiento de la red de entes externos que colaboran con la organización.

\section{MOE 4: El Modelo Integrado Relacional}

Este modelo de Dirección General de Deportes combina la plena integración en las dinámicas de funcionamiento interno del Departamento de Cultura con el desarrollo de la actividad a través de una red externa de organizaciones. Manteniendo las ventajas derivadas de las economías de escala asociadas a la adscripción al Departamento, se reforzaría el núcleo duro de actividades de carácter estratégico de la Dirección General de Deportes, centrada en el diseño de políticas y programas concretos y en control, seguimiento y evaluación de su nivel de consecución.

Aparte del mantenimiento de ciertas actividades que se desarrollan actualmente y que no son susceptibles de ser des- centralizadas, la Dirección General de Deportes impulsaría nuevas áreas de actividad en el campo de la planificación y la evaluación de las actuaciones que realizasen las organizaciones vinculadas, además de supervisar el grado de cumplimiento efectivo de los programas impulsados en los diferentes ámbitos.

En cuanto a la estrụctura, el impacto de la integración al Departamento tendría una mayor repercusión en las unidades que prestan servicios internos y de apoyo a la actividad, en la medida que existan otras unidades que realicen las mismas tareas en el Departamento y que pudiesen compartir tareas. Por lo que se refiere a las unidades vinculadas a la actividad desarrollada por la Dirección General de Deportes, se produciría un importante proceso de reciclaje de aquellas más vinculadas a la implementación de programas concretos, en favor de aquellas unidades que desarrollan actividades de carácter estratégico, de control y de seguimiento de las funciones desarrolladas por la red de organizaciones internas vinculadas a la realización de las actuaciones programadas.
* Una versión preliminar de este artículo se presentó en el IV Congreso Español de Ciencia Política y de la Administración, en el Grupo de Trabajo Gestión Pública e Innovación. Análisis de Experiencias, dentro del Área de Administración y Políticas Priblicas.

** Profesores de Ciencias Políticas y de la Administración de la Universitat Pompeu Fabra.
1 En los tres estudios de caso los dos autores de este artículo fueron los encargados de realizar los MOEs y los CEOs como paso previo a la elaboración de una auditoría organizativa. En el caso del Instituto de Estadística participó también, como director del proyecto, el profesor Joan Subirats. Los tres estudios se han realizado entre 1997 y 1998. No se identifican las Administraciones estudiadas para mantener la confidencialidad. En todo caso, hay que señalar que los tres ámbitos de gestión analizados pertenecen a Administraciones distintas.

\section{Bibliografía}

Bunno, E. (1987), Dirección Estratégica de la Empresa, Madrid: Pirámide.

Galbrat7r, J. R. (1993), «La estrategia y la Planeación Organizacional», en Mintz. berc, H., y Quinn, M. (1993), El Proceso Estratégico, México: Prentice Hall.

Garcin Falcón, J. M. (1995), Dirección Estrategica, Las Palmas: CIES.

GIL, M. A. (1999), Dirigir y Organizar en la Sociedad de la Información, Madrid: Pirámide.

LOPEZ, E. (1989), Técnicas de Control de Ejecución en la Dirección Estratégica de la Administración Pública, Madrid: MAP.
Mas, J., y Ramió, C. (1997), La Auditoría Operativa en la Práctica. Técnicas de Mejora Organizativa, Barcelona: Marcombó Boixareu Editores.

REDdin, B., y Ryan, D. (1995), Manual de Dirección por Objetivos, Bilbao: Deusto.

RuCHaRDs, S. (1996), «New Labour - New Civil Service», en Political Quarterly, vol. 67, Iss. 4.

Waterman, R. H.; Peters, T. J., y Philups, J. R. (1993), «El Esquema de los 7 Círculos», en Mintzberg, H., y Quinn, M. (1993), El Proceso Estratégico, México: Prentice Hall.

Zerlu, A. (1989), Fundamentos de Organización y Dirección General, Bilbao: Deusto. 
